\title{
ANESTÉSICOS LOCALES EN OFTALMOLOGÍA
}

\section{LOCAL ANESTHESICS IN OPHTHALMOLOGY}

\author{
ALBERTE-GONZÁLEZ A ${ }^{1}$, GALLEGO-PINAZO R², PINAZO-DURÁN MD ${ }^{3}$
}

Desde tiempo inmemorial, el hombre ha buscado la forma de aliviar su dolor, aunque no fue hasta el año 3.000 A.d.C., en la antigua Mesopotamia, cuando surgió el primer texto médico en el que aparece el opio como remedio frente a las dolencias. En el papiro de Ebers (s. XVI A.d.C.) se describen varias recetas contra el dolor a base de raíces de eneldo, mirto y raíz de mandrágora. La palabra an-estesia procede del griego «privación de sentido» (1). Desde la utlilización de la cocaína como anestésico local por Karl Koller en 1884 han ido apareciendo hasta nuestros días una gran variedad de anestésicos. Los que presentan menor toxicidad, son utilizados usualmente en forma de distintas técnicas: general, retrobulbar, peribulbar, subtenoniana, subconjuntival y tópica $(2,3)$.

Los anestésicos locales son fármacos que aplicados a concentración suficiente en su lugar de acción, impiden la conducción de impulsos eléctricos por las membranas del nervio y el músculo de forma transitoria y predecible, originando la pérdida de sensibilidad en una zona del mismo. Las señales nerviosas se transmiten mediante potenciales de acción, es decir, cambios rápidos del potencial de membrana que se extiende rápidamente por toda la fibra nerviosa. En condiciones normales la membrana celular se encuentra en un estado de reposo con una diferencia de voltaje transmembrana de -60 $-90 \mathrm{mV}$ (potencial de reposo), en el cual la conductancia a los iones $\mathrm{k}+$ es $50-100$ veces superior al de los iones $\mathrm{Na}+$. Ante la aparición de un estímulo eléctrico se activan los canales de $\mathrm{Na}+$ de la membrana permitiendo la entrada masiva del mismo al interior despolarizándose la célula y alcanzando un potencial positivo de $+10+40 \mathrm{mV}$ (potencial de acción). Posteriormente se produce una disminución de la permeabilidad del canal de $\mathrm{Na}+\mathrm{y}$ una salida de $\mathrm{K}+$ al exterior celular por gradiente de concentración (fase de repolarización), que se continua hasta alcanzar el potencial de reposo inicial mediante un mecanismo activo dependiente de la bomba $\mathrm{Na}+\mathrm{K}+$ que introduce iones $\mathrm{K}+\mathrm{y}$ extrae iones $\mathrm{Na}+$ (en presencia de ATP) a nivel celular

Los anestésicos locales impiden la propagación del impulso nervioso disminuyendo la permeabilidad del canal de sodio, bloqueando la fase inicial del potencial de acción. Para ello han de atravesar la membrana nerviosa puesto que su acción farmacológica se realiza mediante unión al receptor transmembrana desde el lado citoplasmático de la misma (4). La acción anestésica se realiza sobre cualquier membrana excitable pudiendo actuar en un indeterminado punto de la neurona o grupo neuronal, incluso en la membrana muscular y en el miocardio.

Su mecanismo de acción viene determinado por (5):

- Tipo de fibra: Actúan sobre todas las fibras nerviosas, siendo más susceptibles aquellas de menor diámetro (fibras $\mathrm{C}$, encargadas del dolor) que las de mayor diámetro (fibras A encargadas de la motricidad) pudiendo originar una analgesia completa sin afectarse la función motora y táctil (bloqueo diferencial).

- Cantidad de anestésico local disponible en el lugar de acción: «Concentración mínima inhibitoria», es decir, la mínima concentración del anestésico local necesaria para bloquear una determinada fibra nerviosa.

- Características farmacológicas.

Desde el punto de vista químico todos los anestésicos presentan una estructura común:

- Una estructura aromática (ácido benzoico o para-aminobenzoico) que es la porción lipófila responsable de la difusión a través de la membrana nerviosa y la fijación en el axoplasma del nervio.

\footnotetext{
1 Doctor en Medicina y Cirugía. Especialista en Oftalmología. Hospital Costa del Sol. Marbella. Málaga. España.

E-mail: antonioalberte@yahoo.es

2 Licenciado en Medicina. Especialista en Oftalmología. Hospital Universitario La Fe. Valencia. España.

3 Coordinador Investigación Departamento de Salud Valencia-Hospital U. Dr. Peset.
} 
- Un grupo amino que es el determinante de la hidrosolubilidad de la molécula, y por tanto, de su difusión y su distribución sanguínea. Se presenta en 2 formas: no ionizada (difunde más fácilmente a través de la membrana del nervio) y forma catiónica (menos difusible, se uniría al receptor de membrana situado en la parte interna axoplásmica).

- Una cadena hidrocarbonada intermedia que se une al núcleo aromático a través de una unión éster o amida. Este tipo de enlace establece el tipo de degradación y metabolización que sufrirá la molécula y permitirá dividir a los anestésicos locales en dos grandes grupos:

1. Tipo éster: cocaína, procaína, tetracaína, benzaocaína.

Son metabolizados a través de la enzima pseudocolinesterasa en el plasma, son de acción rápida y de corta duración. Dan como metabolito principal el ácido para-aminobenzoico (PABA), un potente alergizante responsable de reacciones anafilácticas.

2. Tipo amida: lidocaína, mepivacaína, bupivacaína, ropivacaína.

Presentan una degradación enzimática por medio de microsomas hepáticos, son de mayor duración y presentan mayor toxicidad.

El objetivo de la anestesia es la producción de un adecuado nivel de bloqueo nervioso con una dosis segura de anestésico local, por ello el conocimiento de sus características y su toxicidad favorecerá un adecuado uso de los mismos, minimizando los riesgos de su aplicación (6).

A pesar de ello, son relativamente frecuentes las reacciones adversas a los anestésicos locales y causa habitual de consultas en alergología, aunque las reacciones severas son excepcionales y representan menos del $1 \%$ de todas las reacciones. Pueden presentarse reacciones adversas no alérgicas ante la administración de un anestésico local (pueden ser tóxicas, no relacionadas con el fármaco, psicomotoras y vasovagales, por estimulación simpática, idiosincrásicas, etc.) o reacciones adversas alérgicas (al propio anestésico local, o a los conservantes y antioxidantes). El riesgo de estas reacciones es directamente proporcional a su concentración en la circulación general, afectándose prioritariamente el sistema nervioso central y cardiovascular.
Por ello, en el caso de cirugía oftalmológica programada, cuando se presenta una reacción adversa al anestésico local, la intervención debe interrumpirse, demorarse y realizar un estudio alergológico para determinar el tipo de anestésico local más seguro para ese paciente. En el caso de que la cirugía sea urgente, la primera elección es la anestesia general, y si ésta estuviera contraindicada (y se conoce la causa de la reacción adversa) se actuará de acuerdo con el siguiente protocolo: 1) si fuera un anestésico local del grupo éster procederíamos a administrar uno del grupo amida, 2) si por el contrario el causante fuera del grupo amida, podemos utilizar otro del mismo grupo o uno del grupo éster (no se producen reacciones cruzadas entre ellos). Y en este sentido hay que tener en cuenta que se han presentado algunos raros excepcionales de alergia a los derivados amida, y en esta ocasión se puede utilizar lidocaína, que habitualmente es bien tolerada, y 3) si no se conociera el agente causante de la reacción, se utilizará un anestésico local del grupo amida, pero sin vasoconstrictores ni conservantes adicionales.

Es importante resaltar la necesidad de conocer el tipo de anestésico local utilizado, sus características y posibles reacciones adversas, así como el reconocimiento precoz de la sintomatología para instaurar medidas terapéuticas que eviten su progresión.

\section{BIBLIOGRAFÍA}

1. Martín Duce A. Historia de la anestesia local. Madrid: Ed Tres Cantos; 2004.

2. Kumar C, Dowd T. Ophthalmic regional anaesthesia. Curr Opin Anaesthesiol 2008; 21: 632-637.

3. Fanning GL. Orbital regional anaesthesia: let's be precise. J Cataract Refract Surg 2003; 29: 1846-1847.

4. Wilson RP. Local anesthesia in ophthalmology. In: Tasman W, Jaeger EA. Duane's Clinical Ophthalmology. Phladelphia:WB Saunders; 1990.

5. López-Timoreda F. Fármacos anestésicos locales. En: Moreno L, Lizasoain I. Velazquez. Farmacología básica y clínica. Madrid: Editorial Médica Panamericana; 2004.

6. Kumar CM. Orbital regional anesthesia: complications and their prevention. Indian J Ophthalmol 2006; 54: 7784 